\title{
Two dimensional echocardiographic diagnosis of partial papillary muscle rupture
}

\author{
RICK A NISHIMURA, CLARENCE SHUB, ABDUL J TAJIK \\ From the Division of Cardiovascular Diseases and Internal Medicine, Mayo Clinic and Mayo Foundation, Rochester, \\ Minnesota, USA
}

SUMMARY Two dimensional echocardiography showed partial rupture of the trunk of the posteromedial papillary muscle after acute inferior myocardial infarction. The findings in this case suggest that partial rupture may be a harbinger of complete rupture.

By virtue of its ability to visualise noninvasively detailed anatomy of cardiac structures in real-time format, two dimensional echocardiography is ideally suited to diagnose mechanical (structural) complications of acute myocardial infarction. Structural disruptions after acute myocardial infarction are uncommon but are potentially correctable with timely diagnosis and treatment. ${ }^{2}$ We describe a patient with acute partial papillary muscle rupture, complicating acute myocardial infarction, diagnosed by two dimensional echocardiography.

\section{Case report}

A 67 year old white man was transferred to the Mayo Clinic for evaluation of cardiogenic shock. He had a history of stable angina but no hypertension or previous myocardial infarction. Two weeks before transfer, the patient sustained an acute inferior myocardial infarction, was admitted to hospital, and was found to be in shock, with pulmonary oedema. Despite initial improvement with medical treatment, he subsequently became hypotensive again and was transferred for further evaluation.

On physical examination, the patient was in respiratory distress. The blood pressure was $100 / 60 \mathrm{mmHg}$ and the pulse $100 / \mathrm{min}$. The jugular venous pressure was raised. Bibasilar râles were noted. The left ventricular impulse, located in the anterior axillary line, was widened and hyperdynamic. No thrill was palpable. A grade 4/6 pansystolic apical murmur and a third sound were present. The remainder of the physical examination was normal.

An electrocardiogram showed sinus rhythm and changes consistent with a recent inferior wall myocardial infarction. The chest $x$-ray film showed cardiac enlargement with pulmonary venous congestion.
Bedside assessment of the haemodynamic data (SwanGanz catheter) is shown in the Table.

Two dimensional echocardiography showed that the left ventricle was moderately dilated with depressed function. There was extensive and severe inferior wall hypokinesis, with involvement of the inferior septum and lateral walls as well, consistent with a large inferolateral wall infarction. The anterior ventricular septum was hyperdynamic. A partial rupture of the trunk of the posteromedial papillary muscle was seen (Fig), with normal coaptation of the mitral leaflets.

Using afterload reduction treatment and positive inotropic agents, the patient's condition remained stable. On the seventh hospital day, the patient suddenly became hypotensive and dyspnoeic, with an increase in the size of the "V" wave on the wedge tracing. This rapid deterioration was thought to be the result of further rupture of the posteromedial papillary muscle. A percutaneous intra-aortic balloon was inserted, and at operation the entire posteromedial papillary muscle was described as necrotic and ruptured. The mitral valve was excised and replaced with an Ionescu-Shiley valve. The patient's condition deteriorated after being taken off the bypass pump, and he died.

Table Haemodynamic data (Swan-Ganz catheter) in patient with partial papillary muscle rupture

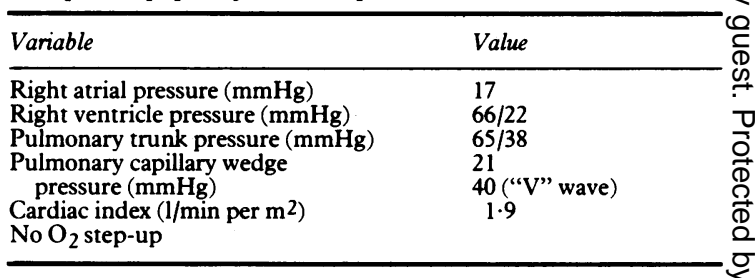



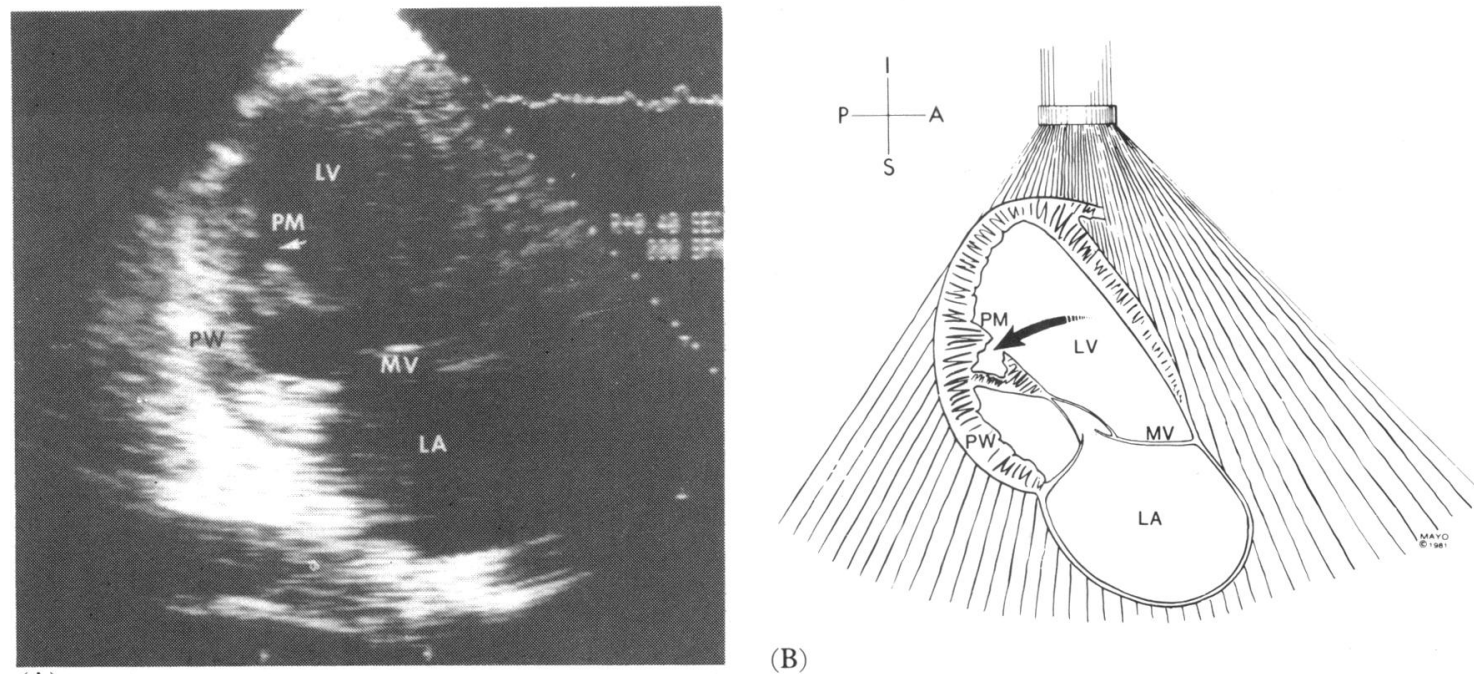

(A)

(B)

Fig. (A) Two dimensional echocardiogram. Apical view showing partial rupture (arrow) of posteromedial papillary muscle (PM). (B) Schematic diagram depicting structures seen in $(A)$. PW, posterior wall; $L V$, left ventricle; LA, left atrium; $M V$, mitral valve.

\section{Discussion}

Rupture of a papillary muscle is a rare complication of acute myocardial infarction, being found in $0.9 \%$ of fatal myocardial infarctions at necropsy. ${ }^{3}$ Rupture of the posteromedial papillary muscle is $250 \%$ more frequent than rupture of the anterolateral muscle, because of the former's single blood supply from the posterior descending coronary artery. ${ }^{4}$ Rupture usually occurs during the second or third day after infarction but may occur later, with immediate death in $33 \%$ and death within 24 hours in $50 \%$ of patients. ${ }^{3}$ Because papillary muscle rupture is usually associated with small areas of necrosis and sparing of the myocardium surrounding the annulus, ${ }^{5}$ early surgical intervention has been suggested to improve an otherwise poor prognosis. ${ }^{6} 7$

Recent reports have described the usefulness of two dimensional echocardiography in the diagnosis of complete rupture of the papillary muscle head(s). ${ }^{8}{ }^{9}$ In our case, the echocardiographic observations suggested that the initial problem was that of partial rupture of the trunk of the posterior papillary muscle. The subsequent sudden clinical deterioration with worsening of mitral regurgitation that occurred several days later represented delayed complete rupture of the papillary muscle (as found at operation).

This observation supports the idea that complete (total) rupture of the papillary muscle may sometimes occur in stages, and that two dimensional echocardiography can be used successfully for diagnosis of partial (early) rupture. Since partial rupture is prob- ably a harbinger of complete rupture of a papillary muscle, visualisation of partial rupture of the trunk by two dimensional echocardiography may help identify high risk patients and may constitute an indication for earlier surgical intervention.

This case further extends the usefulness of two dimensional echocardiography in elucidating the cause of sudden haemodynamic deterioration after acute myocardial infarction.

\section{References}

1 Fox AC, Glassman E, Isom OW. Surgically remediable complications of myocardial infarction. Prog Cardiovasc Dis 1979; 21: 461-84.

2 Kouchoukos NT. Surgical treatment of acute complications of myocardial infarction. Cardiovasc Clin 1981; 11 (no. 3): 141-9.

3 Sanders RJ, Neubuerger KT, Ravin A. Rupture of papillary muscles: occurrence of rupture of the posterior muscle in posterior myocardial infarction. Dis Chest 1957; 31: 316-23.

4 Roberts WC, Perloff JK. Mitral valvular disease: a clinicopathologic survey of the conditions causing the mitral valve to function abnormally. Ann Intern Med 1972; 77: 939-75.

5 Wei JY, Hutchins GM, Bulkley BH. Papillary muscle rupture in fatal acute myocardial infarction: a potentially treatable form of cardiogenic shock. Ann Intern Med 1979; 90: 149-53.

6 Buckley MJ, Mundth ED, Daggett WM, Gold HK, Leinbach RC, Austen WG. Surgical management of ventricular septal defects and mitral regurgitation complicating acute myocardial infarction. Ann Thorac Surg 1973; 16: 598-607. 
7 DeBusk RF, Kleiger RE, Ebnother CL, Daily PO, Harrison DC. Successful early operation for papillary muscle rupture. Chest 1970; 58: 175-8.

8 Mintz GS, Victor MF, Kotler MN, Parry WR, Segal BL. Two-dimensional echocardiographic identification of surgically correctable complications of acute myocardial infarction. Circulation 1981; 64: 91-6.
9 Erbel R, Schweizer P, Bardos P, Meyer J. Twodimensional echocardiographic diagnosis of papillary $\stackrel{\vec{\rho}}{+}$ muscle rupture. Chest 1981; 79: 595-8.

Requests for reprints to Dr R A Nishimura, c/o Section of Publications, Mayo Clinic, Rochester, Minnesota 55905, USA. 